\title{
A study on the usage of mass media by adolescents
}

\author{
MINAKSHI GAUTAM* AND INDIRA BISHNOI \\ Department of Home Science Extension Education and Communication Management, \\ Faculty of Science, College of Home Science, Banaras Hindu University, VARANASI (U.P.) INDIA
}

\begin{abstract}
In the present era of technology mass media is one of the most important of everyone's life and it is difficult to survive without mass media and communicating to each other. In $21^{\text {st }}$ century technological advancement had influenced every aspects of our life and with this change the use of mass media is drastically expanded and took a significant place in almost all the fields. Mostly used mass media is electronic media as in this period of digitization the use of computer, television, internet etc. became the powerful and the most effective instruments of spreading or sharing information. In the past few year the teaching pattern is also changed which influenced the students to adopt and use mass mediums which are easily assessable to them. Today's generation is highly using these mediums for getting information, dissemination of information, for expressing and sharing views, opinion and ideas, advertising, marketing and also for entertainment. Hence, this study was conducted to find out the use of mass mediums (electronic media), pattern of using mass mediums for information and mark out the purpose and time spends by the adolescents, for which 120 school going children between 11 years age group were selected through random sampling technique. A self-structured questionnaire was used to assess the mass mediums media (electronic media) usage. The results revealed that majority of students i.e. 39.16 per cent use mass medium for getting new ideas and information, 25.83 per cent for creating awareness, 21.66 per cent for entertainment and 13.33 per cent for other purpose.
\end{abstract}

KEY WorDS : Adolescents, Electronic media, Usage pattern, Communication

View Point Article : Gautam, Minakshi and Bishnoi, Indira (2017). A study on the usage of mass media by adolescents. Internat. J. Home Sci. Extn. \& Comm. Manage., 4 (1): 39-42. DOI : 10.15740/HAS/IJHSECM/4.1/39-42.

Article History : Received : 04.11.2016; Revised : 30.11.2016; Accepted : 17.12.2016

* Author for correspondence. Department of Extension Education and Management, College of Home Science, Punjab University, LUDHIANA (PUNJAB) INDIA (Email : minakshi0607@gmail.com) 